\title{
Case series on mullerian anomalies incidence during caesarean section over one year period
}

\author{
Mukta Jain, Komal Vijaywargiya, Aayushi Ruia*
}

Department of Obstetrics and Gynaecology, P. C. Sethi Hospital, Indore, Madhya Pradesh, India

Received: 28 October 2021

Revised: 03 December 2021

Accepted: 04 December 2021

\section{*Correspondence:}

Dr. Aayushi Ruia,

E-mail: aayushiruia04@gmail.com

Copyright: ( ) the author(s), publisher and licensee Medip Academy. This is an open-access article distributed under the terms of the Creative Commons Attribution Non-Commercial License, which permits unrestricted non-commercial use, distribution, and reproduction in any medium, provided the original work is properly cited.

\begin{abstract}
Congenital uterine anomalies occur due to abnormal fusion of Mullerian duct during embryonic life. It is associated with high incidences of reproductive failures and adverse obstetrical outcomes. It may be associated with malpresentation, preterm labour or recurrent pregnancy losses. The association of congenital anomalies and early pregnancy loss has been well established but its adverse effect on late pregnancy in form of malpresentation, preterm deliveries has not yet been elaborated. Hence, this case series aimed to summarize the incidence and perinatal outcome of pregnancy in women with congenital uterine anomalies undergoing cesarean section. This was a case series which was conducted on women who underwent cesarean section at P. C. Sethi hospital, Indore between time period of October 2020 to September 2021. Out of total 1835 cesarean undergoing patients, 12 patients were found to have uterine anomalies. Out of 12 patients, 9 (75\%) patients were associated with malpresentation, $4(33.3 \%)$ patients had preterm delivery and $6(50 \%)$ patients had low birth weight babies. Hence it can be said that women with congenital uterine anomalies were at higher incidence of malpresentation and preterm deliveries. Presence of congenital uterine anomalies were associated with adverse obstetrical outcome. This knowledge warrants the need for a larger case control study to extrapolate these findings to the general population and also to recommend the need for universal prenatal screening for uterine anomalies to improve the obstetrical and perinatal outcome in patients with uterine anomalies.
\end{abstract}

Keywords: Mullerian anomaly, Malpresentation, Preterm labour, Low birth weight babies

\section{INTRODUCTION}

Mullerian duct anomalies are congenital anomalies of the female genital tract arising from abnormal embryological development of the Mullerian ducts. ${ }^{1}$ These abnormalities can include failure of development, fusion, canalization or reabsorption, which normally occurs between 6 and 22 weeks in utero. Most sources estimate an incidence of these abnormalities to be 0.5 to $5.0 \%$ in the general population. Septate uterus is the commonest uterine anomaly with a mean incidence of $\sim 35 \%$ followed by bicornuate uterus $(\sim 25 \%)$ and arcuate uterus $(\sim 20 \%){ }^{2} \mathrm{~A}$ didelphys uterus, also known as a double uterus, is one of the least common amongst MDAs. Duplication of the uterus results from lack of fusion of paramesonephric ducts in a local area or throughout their normal line of fusion. In uterus didelphys, individual horns are fully developed, normal in size with two cervices present. Each uterus has one fallopian tube. Some patients are asymptomatic while some patients suffer with primary infertility. ${ }^{3}$ In some patients, normal pregnancy can occur but obstetrical complications such as spontaneous abortion, still birth, preterm birth, malpresentation are frequent. $^{3}$

Unicornuate and didelphys uterus have term delivery rates of $\sim 45 \%$ and the pregnancy outcome of patients with untreated bicornuate and septate uterus is also poor with term delivery rates of only $\sim 40 \% .^{3}$ Arcuate uterus is 
associated with a slightly better but still impaired pregnancy outcome with term delivery rates of $\sim 65 \%$.

\section{CASE SERIES}

Out of total 1835 caesarean section undergoing patients, 12 patients were found to have uterine anomalies. Out of 12 patients, $9(75 \%)$ patients had associated malpresentation, $4(33.3 \%)$ patients had preterm delivery and $6(50 \%)$ patients had low birth weight babies. Hence it can be said that women with congenital uterine anomalies were at higher incidence of malpresentation and preterm deliveries.

Table 1: Distribution of Mullerian anomalies.

\begin{tabular}{|ll|}
\hline Type of anomaly & $\begin{array}{l}\text { Percentage (out } \\
\text { of 12) }\end{array}$ \\
\hline Unicornuate uterus & 41.66 \\
\hline Bicornuate uterus & 33.33 \\
\hline Arcuate uterus & 16.66 \\
\hline Septate uterus & 8.33 \\
\hline
\end{tabular}

Table 2: Percentage of various fetal presentations associated.

\begin{tabular}{|ll|}
\hline Presentations & Percentage \\
\hline Cephalic & 25 \\
\hline Podalic & 58.33 \\
\hline Shoulder & 16.66 \\
\hline
\end{tabular}

Table 3: Perinatal outcome associated with anomalies.

\begin{tabular}{|lll|}
\hline $\begin{array}{l}\text { Type of } \\
\text { anomaly }\end{array}$ & $\begin{array}{l}\text { Percentage of low } \\
\text { birth weight of } \\
\text { baby }(\%)\end{array}$ & $\begin{array}{l}\text { Gestational } \\
\text { age at birth }\end{array}$ \\
\hline $\begin{array}{l}\text { Unicornuate } \\
\text { uterus }\end{array}$ & 4 out of $5=80$ & $\begin{array}{l}3 \text { were preterm } \\
\text { (less than } 37 \\
\text { weeks) }\end{array}$ \\
\hline $\begin{array}{l}\text { Bicornuate } \\
\text { uterus }\end{array}$ & 2 out of $4=50$ & $\begin{array}{l}\text { l case was } \\
\text { preterm, other } \\
\text { early term }\end{array}$ \\
\hline Arcuate uterus & 0 & $\begin{array}{l}\text { Both were late } \\
\text { term }\end{array}$ \\
\hline Septate uterus & 0 & $\begin{array}{l}\text { Case was at } \\
\text { term }\end{array}$ \\
\hline
\end{tabular}

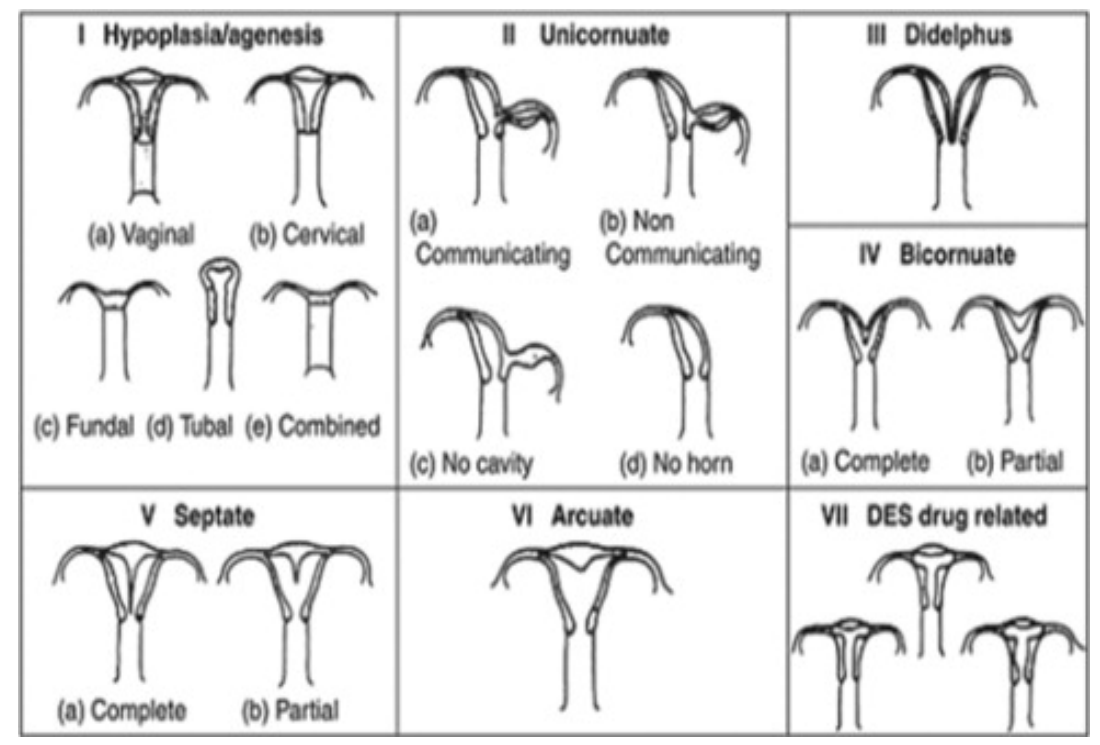

Figure 1: Classification of Mullerian anomalies by American fertility society.

\section{Case presentation}

There were 5 cases with unicornuate uterus which were detected on either antenatal routine ultrasonography on outpatient visits, out of which 2 were incidentally detected during caesarean section for first stage labour arrest and fetal distress. In these women 4 had podalic presentations which were seen on per abdomen and per vaginal examinations. 3 babies were born before 37 completed weeks of gestation and 4 had low birth, thus were admitted for observation in neonatal intensive care unit.

4 cases presented with bicornuate uterus landing up in emergency section, one had non communicating rudimentary horn with podalic presentation, with baby weight just $1.8 \mathrm{kgs}$ and was preterm. Other 3 cases had shoulder presentation in 2 of them and one baby was in low birth weight category. 
In other 3 cases in which 2 had arcuate uterus and one with partial incomplete septum were discovered incidentally during cesarean section and had cephalic presentation, were delivered at term gestation and had birth weight above $2.5 \mathrm{kgs}$.

\section{DISCUSSION}

Mullerian anomalies prevalence was exactly unknown. But recent study showed it was 0.1 to $10 \% .^{2}$ Incidence of singleton pregnancy in uterine didelphys was 1 in 3000 , incidence of twin gestations was 1 in 5 million and incidence of triplets in uterine didelphys was 1 in 25 million. Embryology: failure of the fusion of two paramesonephric ducts, completed non fusion resulted in uterine didelphys, partial fusion of Mullerian ducts resulted in bicornuate and septate uterus.

\section{Classification $^{8}$}

The most recent and widely used classification systems for the different types of Mullerian duct abnormalities were created by Buttram and Gibbons and the American fertility society. When classifying these anomalies solely based on abnormal development, four major types were apparent. Complete or partial failure of Mullerian duct development (agenesis; unicornuate uterus without a rudimentary horn); failure of ducts to canalize (unicornuate uterus with a rudimentary horn without proper cavities); incomplete fusion of Mullerian ducts (bicornuate or didelphys uterus; incomplete reabsorption of uterine septum (septate or arcuate uterus).

\section{Various methods of investigations ${ }^{4}$}

Investigations were usually prompted on the basis of such findings as well as when reproductive problems were encountered. Helpful techniques to investigate the uterine structure were transvaginal ultrasonography and sonohysterography hysterosalpingography, MRI and hysteroscopy, laparoscopy/laparotomy.

\section{CONCLUSION}

Congenital uterine anomalies are common but their effect on reproductive outcome is unclear. Many studies were conducted which showed relation between uterine anomalies and infertility or recurrent pregnancy losses, but its effect on later trimester of pregnancy is less studied.
From this case series it was found that occurrence of malpresentation, preterm deliveries and low birth weight is higher in women with congenital uterine anomalies. Hence it can be concluded that presence of uterine anomalies are a risk factor for preterm delivery, malpresentation and low birth weight baby. This knowledge can be used to recommend screening for uterine anomalies in women with recurrent pregnancy losses, previous low birth weight babies or malpresentation in previous pregnancy.

\section{Funding: No funding sources \\ Conflict of interest: None declared \\ Ethical approval: Not required}

\section{REFERENCES}

1. Rao SS, Anitha GS, Chandralekha P. Pregnancy in uterus didelphys delivered by caesarean delivery: case report. Int J Reprod Contracept Obstetr Gynaecol. 2016;5(7).

2. A Retrospective Study To Find The Incidence Of Uterine Anomalies In Patient Undergoing Cesarean Section, And Their Obstetrical Outcome. Dr Kirti Solanki , Dr Swati Kochar, Dr Priyanka Gaur, Dr Laxmi Poonia, Dr Krishna.

3. Ribeiro SC, Tormena RA, Peterson TV, Gonzáles MDO, Serrano PG, Almeida JAMD, et al. Müllerian duct anomalies: review of current management. Sao Paulo Med J Rev Paul Med. 2009;127(2):92-6.

4. Grimbizis GF, Camus M, Tarlatzis BC, Bontis JN, Devroey P. Clinical implications of uterine malformations and hysteroscopic treatment results. Hum Reprod Update. 2001;7(2):161-74.

5. Chan YY, Jayaprakasan K, Zamora J, Thornton JG, Raine-Fenning N, Coomarasamy A. The prevalence of congenital uterine anomalies in unselected and high-risk populations: a systematic review. Hum Reprod Update. 2011;17(6):761-71

6. Acien P. Incidence of mullerian defects in fertile and infertile women. Hum Reprod. 1997;12(7):1372-6.

7. Buttram VC, Gibbons WE. Müllerian anomalies: a proposed classification (an analysis of 144 cases). Fertil Steril. 1979;32(1):40-6.

8. The American Fertility Society classifications of adnexal adhesions, distal tubal occlusion, tubal occlusion secondary to tubal ligation, tubal pregnancies, mullerian anomalies and intrauterine adhesions. Fertil Steril. 1988;49(6):944-55.

Cite this article as: Jain M, Vijaywargiya K, Ruia A Case series on mullerian anomalies incidence during caesarean section over one year period. Int J Reprod Contracept Obstet Gynecol 2022;11:243-5. 